\title{
Persistence of acquired meaning in semantic conditioning
}

J. P. DAS, UNIVERSITY. OF CALIFORNIA, LOS ANGELES

A. K. MITRA, UTKAL UNIVERSITY, BHUBANESWAR, INDIA

\begin{abstract}
College students learned to associate "good" and "bad" separately to two nonsense syllables (described to Ss as names of two aboriginal tribes), both in the acquisition and in the reversal phases of a verbal conditioning task. But when asked to give evaluative ratings for the syllables, their judgments appeared to be influenced by their experience during the acquisition phase.

\section{Problem}

Meaning can be acquired, and pre-established meaning can be reversed. Staats \& Staats (1958) as well as Das \& Nanda (1963) have shown that acquisition of meaning is easily demonstrated. Apparently, a word can take on the meaning of even its antonymunder certain conditions (Staats, Staats, \& Biggs, 1958). The authors of that study showed that words like "unfair" and "awful" were rated as pleasant after associating them with a set of highly favorable words.

But in the present study, we find that affective characteristics acquired by certain nonsense syllables persist even though $\mathrm{S}$ on a subsequent phase learns to associate with the syllables words which convey just the opposite effect. The experiments describe the conditions for such an unusual finding.

\section{Experiment I}

The conditioning technique employed here has been previously used with success and can be appropriately described as a mediational learning paradigm (Das \& Nanda, 1963). Briefly, if $\mathrm{J}$ (JAGAPA) and $\mathrm{K}$ (KACHADA) were two nonsense syllables, by pairing $J$ with the word "good" on $80 \%$ of the trials and "bad" on $20 \%$ of the trials while adopting the opposite procedure for $K$, it was shown that $J$ was favorably evaluated and $K$ unfavorably so at the end of this procedure. Reversal was introduced at the end of the acquisition period with "bad" substituted for "good" and vice versa, and continued for as long a period as acquisition. Then, $\mathrm{J}$ and $\mathrm{K}$ were evaluated. Either $\mathrm{J}$ will be unfavorably valued and $K$ favorably as a result of reversal, or its opposite will occur. A third possibility will be that both $\mathrm{J}$ and $\mathrm{K}$ will receive neutral ratings, showing partial resistance to the effects of reversal.

\section{Design and Procedure}

Two experimental groups were employed. One of the groups had a .80 probability of "good" following the nonsense syllable $\mathrm{J}\left(\mathrm{J}_{80}\right)$ and .20 following $\mathrm{K}\left(\mathrm{K}_{20}\right)$. For the other control group these probabilities were reversed $\left(\mathrm{J}_{20} \mathrm{~K}_{80}\right)$. Thus one experimental group had
$\mathrm{J}_{80} \mathrm{~K}_{20}$ for acquisition and $\mathrm{J}_{20} \mathrm{~K}_{80}$ for reversal, whereas the other had $\mathrm{J}_{20} \mathrm{~K}_{80}$ for acquisition and $\mathrm{J}_{80} \mathrm{~K}_{20}$ for reversal. Every group received seven blocks of 20 trials each for $\mathrm{J}$ and $\mathrm{K}$ during acquisition and an additional seven blocks for reversal. Details of procedure are given elsewhere (Das \& Nanda, 1963). The nonsense syllables were described to Ss as names of two aboriginal tribes.

The effect of the acquisition and reversal trials was measured in two ways: (1) by requiring $\mathrm{Ss}$ to choose 10 adjectives for $J$ and for $K$ from a list of randomly presented 10 favorable and 10 unfavorable adjectives, and (2) by rating $\mathrm{J}$ and $\mathrm{K}$ on a "Good-Bad" sematic differential.

All Ss were male undergraduate college students in their first or second years in a college in India. There were $20 \mathrm{Ss}$ in each group.

\section{Results}

The data showed that learning did occur in both acquisition and reversal phase of the test. In the two groups, the response probability approximated the input probability both in acquisition and in reversal.

Judgments of $\mathrm{J}$ and $\mathrm{K}$ were consistent with their associations during acquisition training rather than with those during reversal. For the group $\left(\mathrm{J}_{80} \mathrm{~K}_{20}\right)$, mean number of favorable adjectives selected for $\mathrm{J}$ is 7.05 as against 2.95 for $K$. Similarly, the mean evaluative ratings of $\mathrm{J}$ and $\mathrm{K}$ on the evaluation dimension are widely different (5.40 and 2.55 respectively).Both the differences have high statistical significance: $t(19)=3.43$ for adjectives; 4.34 for ratings. Similarly, in experimental group II $\left(\mathrm{J}_{20} \mathrm{~K}_{80}\right)$, $\mathrm{J}$ has a mean favorable adjective choice of 2.40 and evaluative rating of 2.50 as against 7.60 and 5.65 for $\mathrm{K}$; the differences are significant: $t(19)=4.54$ for adjectives; 4.67 for ratings.

\section{Experiment II}

Since the above results were new, there arose the need to replicate the study. In the second experiment, $100 \%$ reinforcement instead of $80 \%$ was introduced; and since learning as well as reversal was expected to be faster under $100 \%$ reinforcement, the number of trials was reduced from 120 to 20 . Two new nonsense syllables, Tarop $(\mathrm{m}=1.24)$ and Latuk $(\mathrm{m}=1.26)$ from Noble's list were chosen as stimuli having low meaning. The sample of 40 Ss were drawn from Introductory Psychology courses at UCLA。

\section{Procedure}

The nonsense syllables were described to Ss as names of two African tribes, Tarop (T) and Latuk (L). T 
and $\mathrm{L}$ were presented through a magnetic tape recorder to two counterbalanced groups of $\mathrm{Ss}, \mathrm{N}=\mathbf{2 0}$ in each group. Group I had $\mathrm{T}_{100} \mathrm{~L}_{0}$ followed by $\mathrm{T}_{0} \mathrm{~L}_{100}$; Group II had $\mathrm{T}_{0} \mathrm{~L}_{100}$ followed by $\mathrm{T}_{100} \mathrm{~L}_{0}$. As in Experiment $\mathrm{I}$, Ss were asked to guess whether "good" or "bad" will follow the stimulus word, to record their anticipations, and score them as correct or incorrect on a form provided for the purpose. As mentioned earlier, $\mathrm{T}$ and $\mathrm{L}$ were presented 20 times each in the acquisition phase, and 20 times in the reversal phase of the task. A similar procedure to that used in Experiment I (choice of adjectives and semantic differential ratings for $T$ and $L$ ) for measuring the effect of the learning treatment was followed here except that Ss were given two evaluative scales to rate $\mathrm{T}$ and $\mathrm{L}$.

\section{Results}

The mean ratings for $\mathrm{T}$ and $\mathrm{L}$ were: $4.42(\mathrm{~T})$, and 3.42 (L) for $\mathrm{T}_{100} \mathrm{~L}_{0} / \mathrm{T}_{0} \mathrm{~L}_{100}$ group; and $2.75(\mathrm{~T})$ and 5.07 (L) for the other group. The data were subjected to a Type I analysis of variance (Lindquist, 1953). The only significant $F$, as expected, was obtained for the difference due to "good"/"bad" associations in the acquisition phase $(\mathrm{F}=12.59$, df 1 and $38, \mathrm{p}<.001)$.

The mean number of favorable adjectives for $L$ was 4.95 in Group I and 7.80 in Group II. This difference was significant at the $5 \%$ level $(t=2.50)$.

\section{Diseussion}

The results clearly show that meaning acquired during the conditioning phase influences the rating of the stimuli following reversal learning. Apparently, these results have great stability; for the persistence of meaning was still obtained in the second set of experiments although not so strongly, which involved a culturally different subject sample, a 100\% reinforcement schedule, and $1 / 6$ th of the number of trials given in the original set of experiments. Although the results are persistent, it is difficult to give any firm theoretical interpretation.

A post hoc explanation may be stated by assuming that during the reversal phase, Ss take their acquisition experience as the frame of reference, and may be responding with appropriate associations during reversal through a mediating code such as "the opposite," or "now reverse." If this was actually the case, $\mathrm{S}$ would reverse in very few trials. Indeed, this was so in two other verbal conditioning experiments (Das, 1961; Das \& Mitra, 1963) as well as in the present one. However, it is not possible to determine from the present data whether persistence of affective meaning is an artifact of the procedure. A large number of acquisition trials given for such simple tasks might raise the possibility of satiation or loss of attention, which would mean that $\mathrm{S}$ no longer pays attention to the reversal phase of the task. Contrary to this assumption, however, in Experiment I, efficient reversal was domonstrated in probability learning; S's mean predictions matched with the input probability. Reversal in the relatively simple task of Experiment II was quite fast. Further research is required to test the generality of the present findings.

\section{References}

Das, J. P. Some correlates of verbal conditioning. Psychol. Stud., $1961,16,30-35$

Das, J. P., \& Mitra, A. K. Relative effectiveness of electric shock and praise and reproof in verbal conditioning. J. gen. Psychol. 1962, 67, 141-146.

Das, J. P., \& Nanda, P. C. Mediated transfer of attitudes. J. abnorm. soc. Psychol., 1963, 66, 12-16.

Lindquist, E. F. Design and analysis of experiments in psychology and education. Boston: Houghton-Mifflin, 1953.

Staats, A. W., \& Staats, Carolyn K. Attitudes established by classical conditioning. J. abnorm. soc. Psychol., 1958, 57, 37-40.

Staats, A. W., Staats, C. K., \& Biggs, D. A. Meaning of verbal stimuli changed by conditioning. Amer. J. Psychol., 1958, 71, 429-431. 